\title{
Congenital pulmonary valve stenosis
}

INSERM

\section{Source}

INSERM. (1999). Orphanet: an online rare disease and orphan drug data base. Congenital pulmonary valve stenosis. ORPHA:3189

Congenital pulmonary stenosis (PS) is a congenital heart malformation (see this term) that is characterized by a right ventricular outflow obstruction with a clinical presentation that may vary from critical stenosis presenting in the neonatal period to asymptomatic mild stenosis. The obstruction in PS can be at the valvular, subpulmonary, or supravalvular levels (valvular, subpulmonary, supravalvular PS; see these terms). 